\title{
Conference Paper WHO Ear and Hearing Disorders Survey: Ecuador National Study 2008-2009
}

\author{
Alejandra Ullauri, ${ }^{1}$ Andrew Smith, ${ }^{2}$ Mauricio Espinel, ${ }^{3}$ Carlos Jimenez, ${ }^{3}$ \\ Cesar Salazar, ${ }^{4}$ and Rodrigo Castrillon ${ }^{5}$ \\ ${ }^{1}$ The University of Chicago Medicine, 5841 S Maryland Avenue, Room 4754 MC 9020, Chicago, IL 60637, USA \\ ${ }^{2}$ London School of Hygiene and Tropical Medicine, UK \\ ${ }^{3}$ Universidad San Francisco de Quito, Ecuador \\ ${ }^{4}$ Hospital San Bartolo Quito, Ecuador \\ ${ }^{5}$ Centro de Otorrinolaringologia Quito, Ecuador
}

Correspondence should be addressed to Alejandra Ullauri; alejandra.ullauri@uchospitals.edu

Received 29 July 2013; Accepted 28 August 2013; Published 27 April 2014

Academic Editors: D. G. Balatsouras, Y. de Roten, A. Franze', and K. Hongo

This Conference Paper is based on a presentation given by Alejandra Ullauri at "The Coalition for Global Hearing Health" held from 3 May 2013 to 4 May 2013 in Nashhville, TN, USA.

Copyright (C) 2014 Alejandra Ullauri et al. This is an open access article distributed under the Creative Commons Attribution License, which permits unrestricted use, distribution, and reproduction in any medium, provided the original work is properly cited.

Objectives. (1) Provide regional governments, institutions, and professionals with local and accurate information on the prevalence of ear and hearing disorders in the Ecuadorian population. (2) Contribute to the global burden of disease by generating standardized data that can be compared among countries and regions. Method. This was a prospective multistage cluster sample design study. Population tested included all members of households selected according to the sample strategy (cluster sample design). Testing was carried out in hospital facilities across the country including audiometry/TEAOEs and otological examination. Results. 5762 subjects were tested, with a global prevalence of hearing disability of $5 \%$ with a $95 \%$ CI of $3.9 \%$ a $6.1 \%$. Out of the total population tested $14.52 \%$ are in need of action or services. Conclusions. The prevalence of disablility in hearing correlates with the prevalence found in other studies using the same protocol. The Ecuadorian population is in need of a substantial improvement in hearing services delivery.

\section{Introduction}

1.1. Global Overview of Ear and Hearing Disorders. Ear disease and hearing impairment are a neglected public health problem in developing countries in the infant and adult populations. According to the measure Year Lived with Disability (YLD) global estimation for 2005 (see Table 1, [1]), hearing loss of adult onset represents the second highest percentage of contributors to the total YLD. Congenital and child-onset hearing loss are also a concern as many of the risk factors can be identified in people from a low socioeconomic background, such as low birth weight, overcrowding, lack of hygiene, and respiratory tract infections, among others. The WHO (World Health Organization) [2, 3] emphasizes three particular facts about hearing loss to support action in this field:

(1) $80 \%$ of deaf and hearing impaired people live in lowmiddle income countries,

(2) 1 of 40 people who would benefit from a hearing aid have one,

(3) $50 \%$ of deafness and hearing impairment are avoidable through prevention, early diagnosis, and management.

A recent literature review [4] searched 3000 studies done since 1980 from around the world. Of these, 108 were selected 
TABLE 1: The leading causes of YLD: global estimates for 2005 [1].

\begin{tabular}{|c|c|c|}
\hline \multicolumn{3}{|c|}{ Years lived with disability (YLD) } \\
\hline & Cause & $\begin{array}{l}\text { Percent of } \\
\text { total YLD }\end{array}$ \\
\hline 1 & Unipolar depressive disorders & 12.1 \\
\hline 2 & Other unintentional injuries & 4.8 \\
\hline 3 & Hearing loss, adult onset & 4.8 \\
\hline 4 & Cataracts & 4.7 \\
\hline 5 & Alcohol dependence & 3.3 \\
\hline 6 & Schizophrenia & 2.8 \\
\hline 7 & Osteoarthritis & 2.7 \\
\hline 8 & Age-related vision disorders & 2.6 \\
\hline 9 & Bipolar affective disorder & 2.5 \\
\hline 10 & Chronic obstructive pulmonary disease & 2.0 \\
\hline 11 & Asthma & 2.0 \\
\hline 12 & Cerebrovascular disease & 2.0 \\
\hline
\end{tabular}

See [1].

for detailed review but only 31 met the following criteria for inclusion:

(i) searched restricted articles published on or after 1980,

(ii) reported prevalence from cross-sectional surveys of representative populations of a country or area of a country,

(iii) results for "persons" and not only for "number or ears,"

(iv) definitions of hearing impairment clearly stated; other definitions were acceptable if thresholds of the hearing levels and frequencies were reported,

(v) reported prevalence of bilateral hearing impairment "better ear," methods described: cross-sectional design, sampling (including methods of randomization), sample size, and sampling and nonsampling errors reported and discussed,

(vi) sample size being sufficient to estimate prevalence with appropriate precision; response rate was $80 \%$ or higher,

(vii) type of audiometric testing, ontological examination, background noise, and location of the examination described.

This information indicates the shortage of data on the prevalence and causes of hearing impairment and its prevalence in the population.

Currently, the WHO aims to eliminate $50 \%$ of the burden of avoidable hearing loss, by working on different areas such as primary ear and hearing care, epidemiology and economic analysis, strategies for prevention, national programs, and raising awareness [5]. The primary ear and hearing care manuals aim at managing ear disease and hearing problems in developing countries. These manuals are divided into three levels: basic, intermediate, and advanced, providing students from different backgrounds with clear information to help prevent, recognize, diagnose, and treat common ear disease and hearing impairment within their communities [6]. Along with training the WHO works on encouraging and assisting countries to develop national programs integrated within the health system or strength existing programs; such examples are those conducted in South East Asia [7]. The prevention takes an important role as well, for which the WHO has developed guidelines for prevention of hearing impairment from ototoxic drugs, chronic otitis media, suppurative otitis media, and noise induced hearing loss, as well as prevention at secondary and tertiary levels [8]. Finally the initiative on epidemiological and economic analysis helps countries to produce reliable data on the current situation in order to plan, develop, and conduct better services than those already existing based on specific findings relevant to the local population's needs [9]. The WHO hearing survey protocol is the result of this initiative.

Since WHO created the WHO Ear and Hearing Disorders Survey Protocol, it has been used in at least 15 surveys in 11 different countries and regions generating standardized data which allows comparison among surveys. Due to differences in population densities and shortage of funds, the WHO ear and hearing surveys were conducted in countries at a provincial or subnational level finding a prevalence of disability in hearing impairment that ranges from 2.07 to $9 \%$ (see Table 2).

This national survey in Ecuador using the WHO protocol is the first survey of prevalence of hearing impairment conducted in this country and in this region on a national scale. The only other successful survey was in Latin America sub-region and was conducted in the city of Canoas, Brazil, in 2003 [10], but this was in only one city and the southern part of a very large country.

1.2. Local Overview on Ear and Hearing Disorders. Prior to this study there were no formal statistics or published studies of prevalence or incidence of deafness and hearing impairment in Ecuador. The pilot study conducted in 2008, previous to the national study, showed a $6 \%$ prevalence of hearing disability in the population tested. One can assume that the lack of studies in the field conducted in Ecuador has an effect on the kind of services currently available. If a government does not have data on the type and degree of the problem its population faces, there is no proper budget allocation and improvement in services delivery.

In 2007, the Ecuadorian government started a new state policy in regard to disability, Ecuador Sin Barreras, to oversee disability developing two main programs: Mision Manuela Espejo y Mision Joaquin gallegos [11]. Mission Manuela Espejo started in November 2009, with the collaboration of 14 government institutions and an agreement with the Cuban government [12]. Cuba contributed with 229 doctors, who together with 120 Ecuadorian doctors started a medical research to diagnose disabilities around the country, to this date (March 2011) identifying 294.611 individuals with disabilities in the country [13].

CONADIS, the National Board for Disabilities, estimates to this date, November 2011, that 213.000 individuals arewith a hearing and speech disability [14]. It recognizes as a disability 
TABLE 2: Countries where the WHO hearing survey has been applied at a national or local scale.

\begin{tabular}{lcccc}
\hline Country & Year & Prevalence of hearing disability & National/subnational level & Regions studied \\
\hline Nigeria & 2000 & $6.2 \%$ & National & 3 \\
Brazil & 2003 & $6.8 \%$ & Subnational & 1 \\
Oman & 1997 & $2.07 \%$ & National & 2 (rural and \\
India & 1997 & $6 \%$ & Subnational & semi-urban setting) \\
Indonesia & 1998 & $5 \%$ & Subnational & 1 \\
Myanmar & 2001 & $8 \%$ & Subnational & 1 \\
Sri Lanka & 2001 & $9 \%$ & Subnational & Jiangsu \\
& 2006 & $5.3 \%$ & & Guizhou \\
China & 2006 & $6.1 \%$ & Subnational & Sichuan \\
& 2006 & $4.9 \%$ & & Jilin \\
Vietnam & 2006 & $4.5 \%$ & National & 6 provinces \\
\hline
\end{tabular}

See [4].

TABLE 3: Population registered with a disability at CONADIS.

\begin{tabular}{|c|c|c|c|c|c|c|c|}
\hline Province & Hearing & Physical & Intellectual & Language & Psychological & Visual & Total \\
\hline Azuay & 1937 & 11443 & 4184 & 322 & 450 & 2086 & 20422 \\
\hline Bolivar & 698 & 2004 & 1036 & 117 & 101 & 615 & 4571 \\
\hline Carchi & 929 & 2303 & 838 & 77 & 237 & 493 & 4877 \\
\hline Cañar & 711 & 2744 & 1298 & 177 & 218 & 601 & 5749 \\
\hline Chimborazo & 1778 & 4311 & 2492 & 118 & 127 & 982 & 9808 \\
\hline Cotopaxi & 975 & 3381 & 1842 & 237 & 171 & 920 & 7526 \\
\hline El Oro & 1367 & 7328 & 4453 & 173 & 745 & 1552 & 15618 \\
\hline Esmeraldas & 859 & 5292 & 2970 & 251 & 244 & 1363 & 10979 \\
\hline Galapagos & 23 & 96 & 85 & 3 & 9 & 22 & 238 \\
\hline Guayas & 7021 & 35112 & 17229 & 903 & 2238 & 7899 & 70402 \\
\hline Imbabura & 1913 & 3743 & 1499 & 140 & 263 & 856 & 8414 \\
\hline Loja & 1434 & 4979 & 3911 & 136 & 548 & 1387 & 12395 \\
\hline Los Rios & 1007 & 9101 & 3232 & 230 & 335 & 1501 & 15406 \\
\hline Manabi & 3148 & 22762 & 5236 & 277 & 3741 & 4918 & 40082 \\
\hline Morona Santiago & 308 & 1686 & 781 & 108 & 156 & 555 & 3594 \\
\hline Napo & 439 & 1599 & 741 & 132 & 68 & 456 & 3435 \\
\hline Orellana & 332 & 1668 & 624 & 102 & 151 & 675 & 3552 \\
\hline Pastaza & 245 & 948 & 458 & 33 & 68 & 265 & 2017 \\
\hline Pichincha & 6549 & 20939 & 9599 & 661 & 1609 & 4901 & 44258 \\
\hline Santa Elena & 700 & 3542 & 1491 & 79 & 166 & 697 & 6675 \\
\hline Santo Domingo de los Tsachilas & 707 & 4172 & 1582 & 84 & 353 & 758 & 7656 \\
\hline Sucumbios & 408 & 2096 & 967 & 72 & 178 & 661 & 4382 \\
\hline Tungurahua & 1488 & 3724 & 2120 & 168 & 254 & 742 & 8496 \\
\hline Zamora Chinchipe & 298 & 1346 & 717 & 61 & 90 & 272 & 2784 \\
\hline Total & 35274 & 156319 & 69385 & 4661 & 12520 & 35177 & 313336 \\
\hline
\end{tabular}

CONADIS 2011 [16].

when a person has one or more irreversible disabilities secondary to genetic illness, congenital or acquires, which persists even clinical or surgical treatment, which also limits a person's ability to perform regular activities, these conditions must be corroborated by clinical or technical assessment [15].

The current distribution of disability by province (Table 3 ) shows 35274 individuals with a hearing disability in Ecuador.
This study's main goal is to contribute with basic data to build hearing services that are efficient and cost effective.

1.2.1. Survey Overview. The population-based survey of prevalence and causes of deafness and hearing impairment and other ear diseases was created in 1995 and published in 1999 by the Program for Prevention of Deafness and Hearing 
Impairment at the World Health Organization in Geneva. It provides a protocol for basic collection of data and it can be adapted for a specific country's needs as long as the collection data remains uniform according to the protocol.

This survey aims to provide countries with

(i) accurate information on the size of the problem,

(ii) an overview of the main causes of deafness and hearing impairment in the area,

(iii) a source of information for prioritization, planning, and resource allocation,

(iv) baseline data for future similar studies,

(v) information that allows the country to compare the cost of the impairment and the costs of impairment prevention,

(vi) standardized information which enables comparison among other countries that have used the same standards.

\subsection{Objectives}

General Objective. Contribute to the global burden of the disease by generating standardized data that can be compared among countries and regions.

Specific Objective. Provide regional governments, institutions, and professionals with local and accurate information on the prevalence of ear and hearing disorders in the Ecuadorian population.

\section{Method and Materials}

\subsection{Study Population. Background information:}

(i) The universe population $=$ Ecuador - corresponds to 13.758.611.

(ii) Average of people living in a household is 4.2 (INEC 2001)

(iii) $95 \%$ confidence interval.

2.2. Ethical Considerations. Prior to conducting the national survey:

(i) the team shared and understood basic concepts,

(ii) the team learned the assessment and analysis methods,

(iii) logistics have been arranged,

(iv) the staff has been trained,

(v) pilot data has been analyzed and used to improve the national survey.

An official signed letter from the Ministry of Health was obtained for identification and information purposes. A letter from the team members explaining the study was also issued to be presented to the households selected. The team members visiting the households received special training in delivering information about the study to subjects and explaining the study's objectives. This training included meetings to revise location maps, sample strategy, techniques to approach households, and so forth. During the household visits the team letter was left with each household to ensure subjects received and understood the study's goals and valuable information to be acquired from its results. Subjects at the households were also informed about their right to decline participation in the study. After the interviewers' presentation of the study, families received written information in order to provide informed consent to participate in this research project. All subjects over 18 years of age signed consent forms prior to testing, and legal guardians signed consent forms for children under the age of 18 . Names of subjects were recorded in the entry sheet and a given number was also assigned at this stage for data processing purposes. The survey software used this number to identify subjects in order to omit names and preserve the subjects' results confidentiality.

2.3. Study Design and Sample Strategy. The national hearing survey took place from March to December 2009 including preparation of materials, training, field work, data processing and analysis, results, and report revision. The universe population was the population of Ecuador which corresponds to 13.758.611. This study followed a multistage sample design. Kalton [18] described a multistage sample study as one that involves a hierarchy of clusters (first large clusters are selected, then some smaller clusters are drawn from the larger clusters, and so on until subjects are selected from the final stage cluster). In this study, the first stage included a cluster sample design; 30 clusters were selected using population proportional to size method (PPS). The second stage included a random selection of neighborhoods within each population selected, then within the neighborhoods; blocks were selected and within the blocks households were selected following again a random selection according to the strategy planned. All members of the households selected were tested.

Adaptation of the WHO Ear and Hearing Disorders Examination Form-Version 7.1 A (see Section 2.5) was used, which includes the following areas: collection of demographic information, hearing examination, basic ear assessment, and cause of ear disease or hearing impairment and action needed.

Testing procedures included 4 stages: (a) collection of demographic and personal information such as name, age, and sex was done. (b) Audiometry for subjects older than 4 years of age included bilateral air conduction thresholds at 1 , 2 , and $4 \mathrm{KHz}$. For subjects 3 years 11 months or younger, transient otoacoustic emissions were conducted in both ears, or behavioral responses to sound were recorded. (c) Otological examination included otoscopy and wax removal if needed. (d) Recommendations were given if medication, additional testing, hearing aids, or others were necessary. (e) Subjects received an incentive (basket with household items such as toilet paper, napkins, and paper towels sponsored by Familia Sancela) thanking them for their time and participation.

2.4. Equipment. The equipment used in this study included 2 screening audiometers, Maico portable screeners, 1 sound 
level meter, 2 otoscopes, 2 front lights, 2 ENT sets for wax removal, 1 TEOAE screener, and 2 laptops.

2.5. Testing Team. The testing team consists of the following:

1 otolaryngologist,

1 speech therapist with audiology training,

1 team visitor,

1 team visitor from the local town (assigned by the local hospital),

1 team coordinator.

2.6. Quality Control. Different procedures were implemented in order to ensure high quality of the study's results.

(i) Testing manuals describe testing procedure and data collection.

(ii) Family information was checked carefully during the testing days, to ensure that the information given by the families during the field visit was the same as the information given at the testing site during testing days. This precaution was taken in order to reduce the probability that subjects who knew that the study was focused on ear and hearing might bring to the testing days other family members known to have a hearing problem to be tested instead of those who lived in the house only. This type of family action would have increased the prevalence of hearing impairment and ear pathology.

(iii) $5 \%$ of the study group to was retested check accuracy of testing and examination.

(iv) Biologic daily calibration of audiometer was checked.

2.7. Diagnostic Criteria. See Table 4.

\section{Results}

3.1. Sample Population. The number of participants was as follows: population number: 7067 subjects in 28 clusters, participants tested: 5762 subjects.

3.2. Logistics Analysis. Families visited was 3660, those who confirmed attendance were $2788(76.20 \%)$, and those who finally came for testing were 1475 (42.20\%) (Figure 1).

3.3. Participants. Subjects who confirmed attendance were 14118 (Figure 2).

Subjects who attended testing days were 5762 (41\%).

Team visitors had to invite nearly 3 times the number of subjects that the sample size required.

Attendance of visited families improved during the national survey by $5 \% .36 \%$ of the families visited actually attended the testing days during the pilot study to $41 \%$ during the national survey. This might be the result of more experience acquired by the visitor team on how to approach families motivating them to attend.

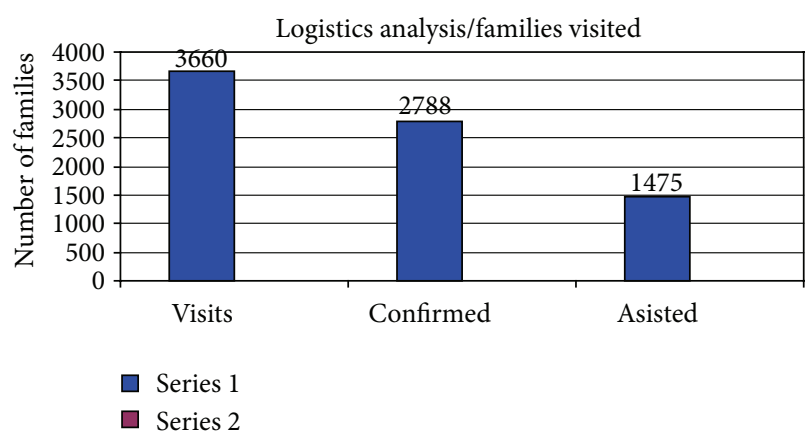

FIGURE 1: Comparison of families visited, those confirming attendance and those who finally attended. WHO Ear and Hearing Disorders Survey: Ecuador.

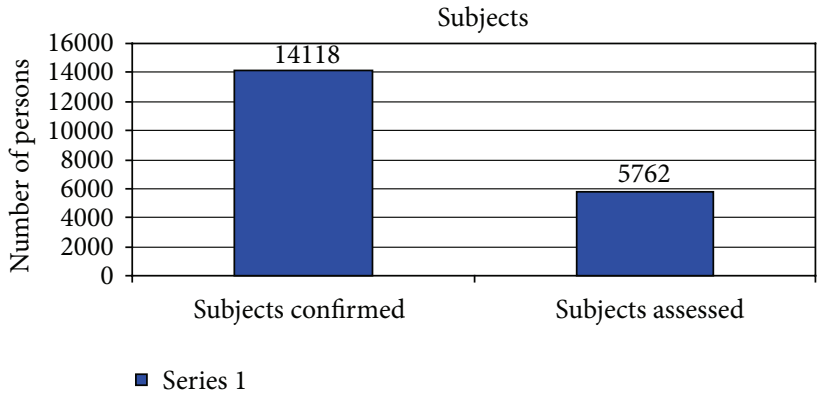

Figure 2: Comparison of subjects confirmed and those who actually attended. WHO Ear and Hearing Disorders Survey: Ecuador.

\subsection{Locations by Clusters. See Table 5.}

3.5. Distribution of Sex and Age of the Sample Population. In Table 6 one can notice that the female population tested was higher by almost $15 \%$ than the male population, especially in the adult population. The difference found in the attendance rate between men and women might be caused by, the assumption that men are more likely to be at work than women.

3.6. Subject with Disability of Hearing Impairment: Binomial Wald. The group 6 of months to 3 yrs 11 months did not have the hearing levels measured but only a pass/fail test based on TEOAE's results and/or the answer (yes, no, and not done) obtained to the following questions stated in the form used in section B (form version 7.1.A):

(1) a child searches for the sound direction and he/she shows some response such as smile or pause when you call his/her name,

(2) a child can point to a parent or brother and sister when you ask, and can speak simple words such as "mama" or "bye bye,"

(3) a child can answer your question for his/her name and can repeat sentences which you give,

(4) a child reflexly blinks to loud noise. 
TABLE 4: WHO grades for hearing impairment [17]. Disability of hearing impairment is defined as moderate or worse hearing loss in the better ear ( $41 \mathrm{~dB}$ average thresholds or greater in persons $15 \mathrm{yrs}$ or older, $31 \mathrm{~dB}$ or greater in children under $15 \mathrm{yrs}$ ). The audiometric ISO values are the averages of values at 500,1000,2000, and $4000 \mathrm{~Hz}$.

\begin{tabular}{|c|c|c|c|}
\hline Grade of impairment & $\begin{array}{l}\text { Corresponding } \\
\text { audiometric ISO value }\end{array}$ & Performance & Recommendations \\
\hline 0 -no impairment & $25 \mathrm{~dB}$ or better (better ear) & $\begin{array}{l}\text { No or very slight hearing } \\
\text { problems. Able to hear } \\
\text { whispers. }\end{array}$ & \\
\hline 1-slight impairment & 26-40 dB (better ear) & $\begin{array}{l}\text { Able to hear and repeat } \\
\text { words spoken in normal } \\
\text { voice at } 1 \text { meter. }\end{array}$ & $\begin{array}{l}\text { Counseling. Hearing aids } \\
\text { may be needed. }\end{array}$ \\
\hline $\begin{array}{l}2 \text {-moderate } \\
\text { impairment }\end{array}$ & 41-60 dB (better ear) & $\begin{array}{l}\text { Able to hear and repeat } \\
\text { words spoken in raised } \\
\text { voice at } 1 \text { meter. }\end{array}$ & $\begin{array}{l}\text { Hearing aids usually } \\
\text { recommended. }\end{array}$ \\
\hline 3-severe impairment & 61-80 dB (better ear) & $\begin{array}{l}\text { Able to hear some words } \\
\text { when shouted into better } \\
\text { ear. }\end{array}$ & $\begin{array}{l}\text { Hearing aids needed. If no } \\
\text { hearing aids available, lip } \\
\text { reading and signing should } \\
\text { be taught. }\end{array}$ \\
\hline $\begin{array}{l}\text { 4-profound } \\
\text { impairment including } \\
\text { deafness }\end{array}$ & $81 \mathrm{~dB}$ or greater (better ear) & $\begin{array}{l}\text { Unable to hear and } \\
\text { understand even a shouted } \\
\text { voice. }\end{array}$ & $\begin{array}{l}\text { Hearing aids may help } \\
\text { understanding words. } \\
\text { Additional rehabilitation } \\
\text { needed. Lip reading and } \\
\text { sometimes signing } \\
\text { essential. }\end{array}$ \\
\hline
\end{tabular}

WHO grades for hearing impairment [17].

TABLE 5: Locations selected according to PPS-census 2001. The last 2 clusters in Guayaquil were cancelled.

\begin{tabular}{|c|c|c|}
\hline Provinces & Town & Cluster \\
\hline \multirow[t]{3}{*}{ Azuay } & Cuenca & 1 \\
\hline & Chillanes & 2 \\
\hline & Mira & 3 \\
\hline Chimborazo & Riobamba & 4 \\
\hline \multirow[t]{3}{*}{ El Oro } & Machala & 5 \\
\hline & Piñas & 6 \\
\hline & Quininde & 7 \\
\hline \multirow[t]{7}{*}{ Guayas } & Guayaquil & $8,9,10, \mathbf{1 1}, \mathbf{1 2}$ \\
\hline & Duran & 13 \\
\hline & Pedro Carbo & 14 \\
\hline & Simon Bolivar & 15 \\
\hline & Otavalo & 16 \\
\hline & Puyango & 17 \\
\hline & Quevedo & 18 \\
\hline \multirow[t]{4}{*}{ Manabi } & Portoviejo & 19 \\
\hline & Jipijapa & 20 \\
\hline & Rocafuerte & 21 \\
\hline & Logroño & 22 \\
\hline \multirow[t]{2}{*}{ Pichincha } & Quito & $23,24,25,26$ \\
\hline & Cayambe & 27 \\
\hline Tungurahua & Ambato & 28 \\
\hline \multirow[t]{2}{*}{ Sucumbios } & Lago Agrio & 29 \\
\hline & Loreto & 30 \\
\hline
\end{tabular}

WHO Ear and Hearing Disorders Survey: Ecuador.
TABLE 6: Distribution by age and sex.

\begin{tabular}{lccc}
\hline Age group & Male & Female & $\begin{array}{c}\% \text { of total } \\
\text { population } \\
\text { tested }\end{array}$ \\
\hline$[0,4]$ & $47.40 \%$ & $52.60 \%$ & $11.30 \%$ \\
{$[5,14]$} & $47.40 \%$ & $52.60 \%$ & $27.60 \%$ \\
{$[15,65]$} & $\mathbf{3 9 . 7 0 \%}$ & $\mathbf{6 0 . 3 0 \%}$ & $54.50 \%$ \\
{$[66,)$.} & $\mathbf{3 8 . 9 0 \%}$ & $\mathbf{6 1 . 1 0 \%}$ & $6.60 \%$ \\
\hline$\%$ of total population tested & $42.60 \%$ & $57.40 \%$ & \\
\hline
\end{tabular}

WHO Ear and Hearing Disorders Survey: Ecuador.

\subsection{Prevalence of Disability of Hearing Impairment by Cluster. See Figure 3.}

3.8. Ear Diseases Found. In Tables 7, 8, 9, and 10, impacted wax is the main problem impacting this population. Cerumen is a preventable cause of hearing and ear diseases and in most cases can be managed at primary health levels. Otitis media results might not reflect the reality of the problem, further information and results in comparison with other studies to be discussed in the discussion section.

3.9. Hearing Impairment versus Occupation. Table 9 shows the high prevalence of hearing impairment in farmers and manufacturing workers, pointing out another vulnerable group. Targeting manufacture workers, protection policies, how they are implemented, quality controls, brings up an important and vulnerable population in need of assistance. 
TABLE 7: Prevalence of hearing impairment by age groups.

\begin{tabular}{|c|c|c|c|c|}
\hline Age & No. of observations & Prevalence & Standard of error & $95 \% \mathrm{CI}$ \\
\hline 6 months to 3 yrs 11 months. & 575 & $4.3 \%$ & $1.8 \%$ & 0.7 a $7.9 \%$ \\
\hline 4 yrs to 14 yrs 11 months. & 1926 & $1.5 \%$ & $0.4 \%$ & 0.6 a $2.3 \%$ \\
\hline 15 years and older & 3179 & $7 \%$ & $0.8 \%$ & 5.4 to .8 .7 \\
\hline 15 yrs to 64 yrs & 2836 & $2.6 \%$ & $0.6 \%$ & 1.5 a $3.7 \%$ \\
\hline $65 \mathrm{yrs}$ and older & 343 & $40.9 \%$ & $5.1 \%$ & 30.9 a $50.9 \%$ \\
\hline Total prevalence & 5619 & $5.0 \%$ & $0.6 \%$ & $3.9 \%$ a $6.1 \%$ \\
\hline
\end{tabular}

WHO Ear and Hearing Disorders Survey: Ecuador.

TABLE 8: Ear disease found according to age group.

\begin{tabular}{|c|c|c|c|c|}
\hline Condition & $6 \mathrm{~m}$ a 3 a $11 \mathrm{~m}$ & 4 a 15 yrs & 16 a 65 yrs & $65 \mathrm{yrs}$ and older \\
\hline Wax & $10.2 \%$ & $13.7 \%$ & $8.4 \%$ & $10.4 \%$ \\
\hline Foreign body & $0.1 \%$ & $1.2 \%$ & $0.1 \%$ & $0.1 \%$ \\
\hline Otitis external & $0.5 \%$ & $1.2 \%$ & $2.4 \%$ & $0.6 \%$ \\
\hline Otitis media acute & $0.0 \%$ & $0.6 \%$ & $0.1 \%$ & \\
\hline Otitis media chronic suppurative & $0.2 \%$ & $0.1 \%$ & $0.7 \%$ & $2.4 \%$ \\
\hline Otitis media serous & $0.2 \%$ & $0.2 \%$ & $1.9 \%$ & $0.6 \%$ \\
\hline Dry perforation or tympanic disease & $0.7 \%$ & $1.0 \%$ & $1.7 \%$ & $2.0 \%$ \\
\hline
\end{tabular}

WHO Ear and Hearing Disorders Survey: Ecuador.

TABLE 9: Hearing impairment detected according to work place.

\begin{tabular}{lccc}
\hline & Impaired & & \\
Occupation & No & Yes & Total \\
\hline Farmer & $64.5 \%$ & $\mathbf{3 5 . 5 \%}$ & $0.8 \%$ \\
Office worker & $94.7 \%$ & $5.3 \%$ & $2.7 \%$ \\
Manufacture & $84.0 \%$ & $\mathbf{1 6 . 0 \%}$ & $2.6 \%$ \\
Student & $97.0 \%$ & $3.0 \%$ & $37.0 \%$ \\
Other & $83.0 \%$ & $17.1 \%$ & $43.1 \%$ \\
Unknown & $74.8 \%$ & $25.2 \%$ & $13.9 \%$ \\
\hline Total & $87.2 \%$ & $12.8 \%$ & \\
\hline
\end{tabular}

WHO Ear and Hearing Disorders Survey: Ecuador.

TABLE 10: Population in need of ear and hearing services.

\begin{tabular}{lcc}
\hline Action needed & Frequency & Percentage \\
\hline Yes & 1,026 & $\mathbf{1 4 . 5 2 \%}$ \\
No & 6,041 & $85.48 \%$ \\
\hline Total & 7,067 & $100.00 \%$ \\
\hline
\end{tabular}

WHO Ear and Hearing Disorders Survey: Ecuador.

3.10. Need of Action in the Total Population. Table 10 shows that $14.52 \%$ of the national population is in need of services. This percentage seems high as it takes into account those in need of further testing to confirm diagnosis, especially children detected with hearing problems during the survey, but who further diagnostic testing.

3.11. Action Needed following This Survey. Table 11 shows that the population in need of services would benefit from otological and audiological services. The "other action" services value reflects the need for audiological testing following this survey to confirm diagnosis.

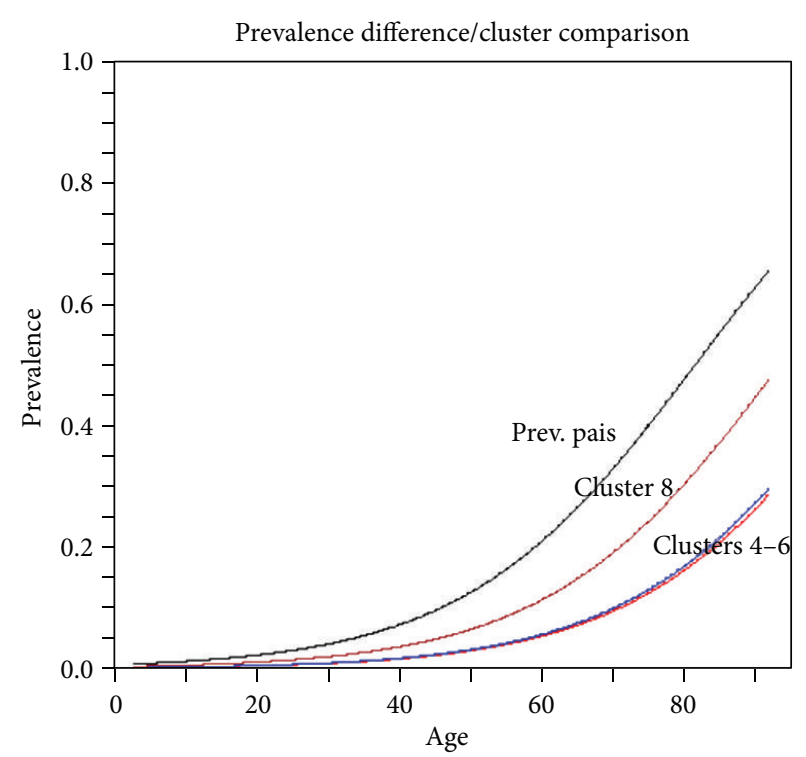

FIgURE 3: Prevalence difference/cluster comparison. WHO Ear and Hearing Disorders Survey: Ecuador.

3.12. Correlation between Age/Sex and Disability of Hearing Impairment. Age and sex do have a significant effect on the disability of hearing impairment, showing that men at an older age are more likely to have a hearing impairment than women (Figure 4).

\subsection{Study Strengths and Limitations}

3.13.1. Strengths. The strengths of this study were as follows:

(i) experienced team supervisors in otology and audiology, 
TABLE 11: Distribution of action needed in the population with any ear or hearing disorder.

\begin{tabular}{|c|c|c|c|c|}
\hline Actions needed & Percentage & Standard of error & LI (95\%) & LS (95\%) \\
\hline Medication & $21.20 \%$ & $2.30 \%$ & $16.60 \%$ & $25.80 \%$ \\
\hline Hearing aid & $24.00 \%$ & $2.30 \%$ & $19.40 \%$ & $28.50 \%$ \\
\hline Language/speech rehabilitation & $0.50 \%$ & $0.30 \%$ & $0.00 \%$ & $1.20 \%$ \\
\hline Special needs education & $2.50 \%$ & $0.80 \%$ & $0.90 \%$ & $4.10 \%$ \\
\hline Vocational training & $0.60 \%$ & $0.50 \%$ & $0.00 \%$ & $1.60 \%$ \\
\hline Surgery referral & $0.80 \%$ & $0.50 \%$ & $-0.20 \%$ & $1.80 \%$ \\
\hline Other action & $50.60 \%$ & $2.60 \%$ & $45.40 \%$ & $55.80 \%$ \\
\hline
\end{tabular}

WHO Ear and Hearing Disorders Survey: Ecuador.

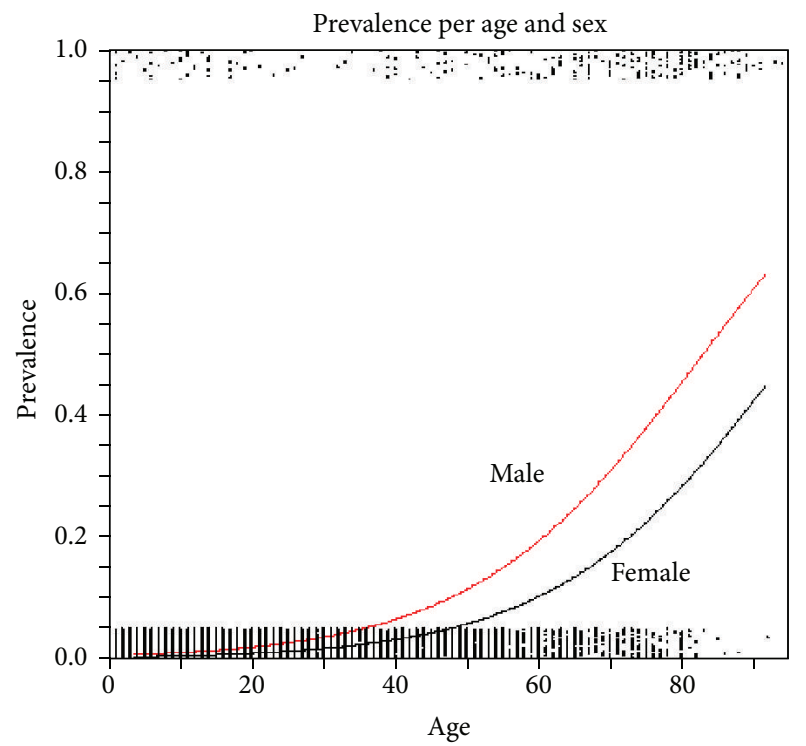

Figure 4: Prevalence of disablility in hearing impairment by sex and age. WHO Ear and Hearing Disorders Survey: Ecuador.

(ii) low rotation of professionals, giving the study consistency in its findings,

(iii) hospital base site for testing,

(iv) local visitor with local knowledge of the area and people,

(v) testing days being conducted during weekends to facilitate attendance.

3.13.2. Limitations. The limitations of this study were as follows.

(i) Due to security issues in Ecuador, it was difficult to approach households for interviews especially in urban areas.

(ii) $40 \%$ of those participants confirmed actually attended the testing day, resulting in more than double the work and resources to recruit families needed in order to complete the sample size required.

(iii) Visual examination of the ear can still have a subjective impact. In this study, although the form is coded and symptoms must be taken into consideration in order to write a diagnosis, it was from our experience that this is still a problem as it has a subjective component among ear, nose, and throat professionals. The results show a very low prevalence of otitis media which do not relate to expected values and need further investigation to rule out an error in its diagnosis.

(iv) Performing tympanometry would have helped with the identification and/or correlation of middle ear pathology, providing an objective assessment of the middle ear. Tympanometry would have assisted clinicians when choosing the code after otoscopy examination. We found that the coding and identification of otitis media was limited in this study.

\section{Discussion}

Smith [19] recognizes that the burden of hearing impairment and disability is currently high and growing, which has a negative impact on individuals, society, and on the economies of countries, as it is a cause and consequence of poverty. WHO estimated that 42 million individuals in the world had disability of hearing impairment in 1985, 120 million in 1995, and 278 million in 2005 [20].

In this study, Ecuador presented a $5 \%$ prevalence of hearing disability in the general population, which correlates with previous studies conducted in Brazil (Canoas) $7.3 \%$, Nigeria (3 regions) 4.4 to $7.6 \%$, and Northern Vietnam $7.8 \%$. China (Jiangsu) and Southern Vietnam reported a lower prevalence of 4.8 and $4.7 \%$, respectively [21], which is higher than the $4.2 \%$ world's global estimation at the time of the study. We did not find a difference among clusters that could suggest a difference among provinces or regions in Ecuador. Our results do not correlate with the population expected with a hearing disability by CONADIS of 213000 , and it does not correlate with the registered number of nearly 35000 individuals in the country, which reflects an under registration of this disability. We could not find the strategy used to calculate the expected number of 213000. According to this year's census, 2011, 14.483.499, 5\% prevalence will mean 724175 Ecuadorians with a hearing disability, which is almost 3.4 times greater than the CONADIS 2011 expectation.

Otitis media results in this study may need revision as the prevalence is very low considering risk factors commonly 
found in developing countries. One hypothesis for this low prevalence is that the diagnosis of otitis media was made by visual observation; ear, nose, and throat specialists had a coding system for symptoms provided by WHO Hearing Survey Protocol in order to classify pathologies and having these parameters could help but the final diagnosis was still left to the specialist subjective impression of each case. External otitis media, was found to have a prevalence between 0.5 and $2.4 \%$ while other studies show a prevalence between 3 and $9 \%$ [22]. Acute otitis media shows a prevalence between 0.0 and $0.6 \%$, which is very low considering that children in developing countries are at a higher risk due to lower immune systems, lack of hygiene, living in crowded households, lower nutritional status, and so forth [23]. Chronic suppurative otitis media's prevalence was found between 01 to $2.4 \%$ in the different age groups. Otitis media serous or with effusion was found to have between 0.2 and $1.9 \%$ prevalence; $0.2 \%$ prevalence was found in the age group of 6 to 47 months, which is known to be the highest risk group, showing in the literature the highest prevalence of this condition between 2 and 5 yrs of age [24]. Aboriginal people in Australia are known for having health problems similar to those living in developing countries; middle ear disease is one of their main problems as it causes hearing loss from a young age that might last a lifetime setting people for lower access to education, social interaction, and poverty. Surveys conducted on aboriginal people in Australia have found that $11 \%$ of people presented with middle ear diseases, 10 to $54 \%$ presented with chronic middle ear disease, 9 to $36 \%$ presented with perforated eardrums, and finally 10 to $41 \%$ presented with deafness [25]. Considering results found in another surveys, the risk factors for otitis media in the developing world, a possible error in our results might rely on the visual examination which might have been impacted by subjective analysis of each ENT professional. Pitkaranta [26] states that in $40 \%$ of the cases doctors do not have certainty of the diagnosis of otitis media. Pitkaranta highlights some of the obstacles for making a reliable diagnosis of OM: adequate light for visual examination of the tympanic membrane, free of wax external ear canals, wax removal prior to examination, and appropriate size of the specula. Additionally, she recognizes short periods of training and courses on otitis media in many of the medical residency programs, as well as lack of use of additional tools such as pneumatic otoscopy and tympanometry. As the hearing survey is a population based study, no further tools such as those mentioned before were available to confirm the diagnosis of OM.

Our action needed results showed that approximately $14.5 \%$ of the population of the country are in need of otological and audiological testing and followup, which can help local health authorities plan strategies to followup with these subjects by networking with local professionals, reporting ear and hearing disorders to a national data base, reinforcing hearing protection in the local farms, factories, and among the community, reinforcing otoscopy and wax management at a general practitioner practice or at the local primary health center within the limits of training of these professionals, and following up with young children to prevent language delays and development of chronic middle ear pathologies.
Strategies for prevention of deafness and hearing impairment can now be analyzed and developed according to the local findings. The WHO has pointed out three main preventable causes of hearing impairment: ototoxic drugs, chronic otitis media, and noise induced hearing loss [27]. Our current results show that farmers and manufacturing workers are at a higher risk of acquiring a hearing impairment; in these types of work places noise may be the cause and this is a preventable cause if well managed. The survey was unable to find ototoxic drugs as a leading cause, but this may be a result of a lack of knowledge of the subjects of the medications used in the past and a lack of a detailed case history that may help to identify ototoxic drugs used previously. As discussed above, otitis media results found in this study show a very low prevalence which needs further investigation to rule out an error in the diagnosis.

Between 8.4 and $13.7 \%$ of the population tested was found to have impacted wax in the ear canal. Primary health centers need to address this by providing proper training for otoscopy and wax removal to general practitioners and nurses and also providing them with information on local ENTs for difficult cases that go beyond their training. The community should also be informed of ways to prevent impacted wax in the ear canals. Training should highlight cases that need to be referred directly to an ENT; such cases might include tympanic perforation, only one hearing ear, abnormal anatomy due to congenital reasons, or postsurgical intervention, among others.

Hearing aid fitting was found to be a need for $24 \%$ of the population in need of services. This highlights the importance and the need to have sustainable programs for hearing aid fitting. This does not only mean fitting, but also selection of those who would benefit from it, the right type of amplification, and monitoring services. Brosch et al. [28] studied rehabilitation through hearing aid fitting in sensory neural hearing losses. They found that the majority of people who did not wear their hearing aids did not perceive a benefit from them. The study included 197 patients; 108 wore their hearing aids all the time, 57 wore them rarely, and 32 never wore them due to inappropriate fitting. This means that $46 \%$ of those who had hearing aids did not wear them. Hearing aid fitting is not only a matter of amplification, but it is also about the right amplification for the right person. Budgeting cannot be performed with the expectation that $46 \%$ of those who receive hearing aids will not wear them. A recent study of 6027 hearing aid users conducted by Bertoli et al. [29] showed that bilateral amplification (for bilateral losses) and advanced signal processing features in hearing aids may contribute to successful hearing aid fitting. Wong and colleagues [30] found that hearing aid performance was the most important element in determining satisfaction. The right selection of hearing aids and the most appropriate fitting contribute to rehabilitation programs that are successful, which in the long run contribute to supporting sustainable hearing aid programs for the population.

Otological clinical services are highly needed, and $22 \%$ of those who need further action are in need of medication. Many pathologies of the external and middle ear can be treated by trained primary and secondary health care 
professionals. Otolaryngologists are concentrated mainly in the cities and the population in need of these services may not necessarily live in the bigger cities or have access to ENT services. This is a very important highlight of the study because it points out the need of primary health workers to become more involved in preventing ear and hearing disorders.

\section{Conclusions}

(i) The prevalence of hearing impairment in Ecuador is similar to the prevalence found in other countries who have applied the same protocol.

(ii) The prevalence of $5 \%$ is higher than the global estimate of $4.2 \%$ at the time of the study [1] and higher than the local estimation by CONADIS.

(iii) Need for action to target ear pathologies and hearing impairment found may now be better planned in this area to reduce the impact of preventable ear diseases, such as impacted wax and noise induced hearing loss.

(iv) Otitis media prevalence needs to be further investigated in this population, and the use of additional tools such as neumatic otoscopy and tympanometry is higly recommended to decrease the degree of error due to subjective visual examination only.

(v) Wax in the ear canal is a preventable cause of future external ear canal pathologies and conductive hearing impairment. Between 8.4 and $13.7 \%$ of the population tested was found to have impacted wax in the ear canal, making this the highest prevalence of ear disease among the population studied.

(vi) Based on the action needed results, $14.52 \%$ of the population of this area might be in need of otological and audiological testing and followup.

\section{Recommendations}

This study's results can be used to improve the services we provide at the moment in the area of ear and hearing. Starting by analyzing the local infrastructure, professional network, and equipment could help us define what percentage of the population identified in this study can receive services at the moment and how to organize and such services prioritize otological appointments, medication for middle ear, hearing assessment for all ages which are and hearing aid services. Once this local assessment is done, professional, and institutions can also identify areas for growth in this field.

Three main areas of work are explained as follows.

\section{Promotion/Prevention}

(1) Prevent Noise Induced Hearing Impairment. Work on national strategies to promote hearing protection at different levels such as families, schools, and industries. Review noise protection government policies, investigate their application among different industries, and inform employers and employees of their responsibilities preventing hearing impairment. Informing, applying, and regulating noise policies in the community and work places will support national strategies. The National Institute on Deafness and Other Communicative Disorders has helped create "It's a noisy planet, protect their hearing" http://www.noisyplanet.nidcd.nih.gov. This website has a very interesting initiative, and it provides information for parents, schools, adolescents, and the community on how noisy our surroundings can be and what we can do about it. They have developed a section of this website in Spanish and are present at most professional meetings providing information on what kind of activities one can conduct according to his/her work site, age group, and so forth.

\section{Primary Services}

(2) Primary Ear Health Care. 8.4 to $13.7 \%$ of the population has impacted ear wax in the ear canal, a problem that can be resolved at primary health care level. A community based approach is recommended. Initially the implementation of a training program for primary health care doctors and nurses at the local health centers to remove wax will help establishing professional networks and reference centers. Such training must focus on ear wax removal in normal ears and highlight those cases that need to be referred to a specialist such as only one hearing ear, operated ear, middle ear prosthesis, perforated ear drums, discharging ears, and so forth. The WHO has developed a manual for primary ear and hearing care manual, which is available at the WHO webpage for download. This three-level set of manuals can be used to train health workers, nurses, and general practitioners in common ear and hearing disorders, how to identify otitis media, remove impacted wax, detect hearing problems, explain options to patients and families, and refer them to specialized centers at the appropriate time. This is a very friendly user manual that can be used at an entry level for community members such as parents and teachers, to a more advanced level such as nurses, health workers, pediatricians, and general practitioners. Remote areas such as the Galapagos islands, the rainforest, where the population not always has access to ear, nose, and throat specialists, community workers could be trained on primary ear health and manage the problem locally so that they can work on stopping ear diseases to become chronic and the disability of hearing losses by acting at an appropriate time and manner.

\section{Secondary Services}

(3) Professional Network. As $14.52 \%$ of the population in this area needs further testing or followup, it is recommended to start developing a network to assist this population at a primary, secondary, or tertiary level depending upon professional training, infrastructure, and equipment available.

(a) Primary Hearing Services. Health centers and mobile units could assist with wax removal services, otitis media diagnosis and medication, referral to other services for further testing, and hearing screening for babies under the age of 12 months. For this type 
of services, trained personnel with basic equipment for wax removal, otoscopes, and portable otoacoustic emissions could assist this population.

(b) Diagnostic Hearing Services. These services could be provided from the public and private sectors depending on the locations in order to cope with the population referred by the primary services provided, as well as those who are on ongoing treatment, and so forth.

(c) Pediatric Hearing Services. The diagnosis of hearing impairment in children requires academic training, experience, and ongoing education as diagnosis of children is not straight forward in many cases, and there are pathologies that we do not fully understand their physiology yet and have different rehabilitative approaches; rehabilitative options are in constant development in order to offer children a better reception of sound. Considering that an accurate diagnosis will help to direct a child to better options for treatment and rehabilitation, the experience of the personnel working with young babies and children is highly needed. One considers that the time and accuracy of the diagnosis make an enormous impact on the speech development in children, which will allow them to access education, work later in life, and fully develop as active members of society; when institutions acknowledge the responsibility a child brings among professionals then they will understand and improve pediatric services. Having specialized pediatric diagnostic centers is basic for the success and sustainability of such programs, and assessed babies and children will be better rehabilitated as well showing spoken language development at a later stage, the capacity to cope with regular schooling, and so forth. Having poorly trained pediatric hearing professionals is one of the main reasons why such programs fail as results are not seen after intervention. The lack of the professionals in the field is a downside in this topic. Audiology and otology does not exist as a career in Ecuador. Speech therapists are usually trained in basic audiology services, but have no training and/or academic education to diagnose and treat hearing impaired children, apply differential diagnosis, and provide the best rehabilitative options available.

(d) Rehabilitation Services. Hearing aid provision and cochlear implant programs for hearing impaired and deaf people are developing in our country in the public sector and have been established prior to the public experience in the private sector. Hearing aids and cochlear implant technology develops every day for one main reason: we are still far from what a normal ear can do; we still do not fully understand part of the physiology of the normal ear and auditory central pathways. Considering this technology continues to develop every day to offer hard of hearing people better opportunities to hear better in order to understand what has been said to them. This brings us to other pillars in rehabilitation, that is, therapeutic resources, ongoing speech, and aural rehabilitation which allow patients to use technology effectively. If one goes back to the physiology of hearing, we hear with our brains, hearing aids, and cochlear implants that allow hearing, but speech and aural rehabilitation allow understanding of what has been heard; without understanding hearing makes no difference. The essence of therapeutic services relies on the combination of technology (better technology every time to improve signal to noise ratio to facilitate understanding) and speech and aural professionals to optimize technology use for understanding purposes. When rehabilitative services are provided in isolation, specially in the pediatric population, the results are limited and definitely not what the institution, parents, and patients expected. Governments could work on strategies to provide services that will have an impact on people's lives and that will improve their activity within society. The creation of rehab units for hearing impaired people that are accessible to them on a regular basis is the main key. Rehab services should not be provided at hospital based centers, as these services are ongoing services and should be separated from hospital/disease association.

(4) Hearing Aid Provision. Hearing aid programs are highly needed; this study shows that $24 \%$ of those in need of services need hearing aid fitting. The highest prevalence of disability of hearing impairment is found in those 65 years of age or older, men being at a greater risk. This information may help to improve hearing aid provision for those in need and also to target the elderly population. Public health policies among the world have helped to increase the life expectancy of the population, which brings up another responsibility to help people grow older but also have a quality of life. The way the population age is changing around the world makes hearing services highly needed as the population gets older and has the highest prevalence of disability of hearing impairment.

(5) Research Needs. This study may help identify areas for further research as follows:

(a) middle ear diseases in the population,

(b) current management of middle ear disease in children,

(c) noise induced hearing impairment in the Ecuadorian population,

(d) effectiveness of current rehabilitative services: pros and cons.

(6) Surveillance Study. In 2014 it will be 5 years since this study took place in Ecuador, and in this period of time the government has implemented different public health policies related to disabilities and hearing disorders have been targeted by many hospitals' programs. A surveillance study could help to monitor the performance and results of those policies in place. The results shown in this study will serve as 
baseline values for comparison when a new study of this type takes place.

\section{Conflict of Interests}

The authors declare that there is no conflict of interests regarding the publication of this paper.

\section{Acknowledgments}

This paper was funded by the CBM and Audiovital with collaboration of the Ministry of Public Health of the Republic of Ecuador and Familia Sancela S.A. The authors would like to thank Dr. Andrew Smith LSHTM, Dr. Mauricio Espinel USFQ, Dr. Carlos Jimenez USFQ, Dr. Benjamin Puertas USFQ and Dr. Susana Rodriguez HPBO for their contribution to this project, CBM; the Ministry of Public Health of the Republic of Ecuador, and Audiovital-Grupo Viennatone, for thier support and contribution towards the planning and implementation of the study; Familia Sancela S.A. for contributing by thanking families participating in this study through a gift of their products; and Dr. Paul Garces, Ms. Marta Silva, Ms. Silvia Tapia, Ms. Fernanda Torres, Ms. Paola Tonato, Ms. Tatiana Calderon, Mr. Nelson Subia, and Mr. Eulofio Rosales for their participation and commitment in the running of this study. The authors would also like to thank Dr. Anna Messner for lending the DPOAE's equipment to an Ecuadorian charity foundation which was used in this study. Additionally, the authors would like to thank the hospitals and professionals from the Ministry of Health who contributed to this study. (1) Hospital Jipijapa-Jipijapa; Dr. Paladines (Director); Lcda. Rosa Villacreses, Trabajadora Social. (2) Hospital Alberto Bufonny-Quinindé; Dr. Fernando Ribadeneira (Director); Ms. Zoila Quiñones. (3) Hospital Abel Gilbert Ponton-Guayaquil; Dra. Subdirectora; Dr. Alfredo Espinel; Lcda. Leticia; Lcda. Grecia. (4) Hospital Natalia Huerta de Niemes-Rocafuerte; Dr. Manolo Vizcaino-Subdirector; Manuel CuadrosPromotor de Salud. (5) Hospital Verdi Cevallos-Portoviejo; Dr. Jhony Merchán (Director); Dra. Carmen CampuzanoSubdirectora; Lcda. Lilia Macias-Trabajadora Social. (6) Hospital Marco Vinicio Iza-Lago Agrio; Dr. Fredy Alvarado (Director); Lcda. Alexandra Plaza-Trabajadora Social Hospitalaria. (7) Hospital San Gabriel-San Gabriel; Dr. William Duran (Director); Dr. Tito Rodríguez (Coordinador); Lcda. Silvia León-Trabajadora Social. (8) Hospital Provincial Docente Ambato-Ambato; Dr. Opilio Cordova (Director); Lcda. Gloria Ramírez (Dirección Provincial de Salud); Lcda. Yolanda Núñez (Consulta Externa). (9) Hospital Docente Riobamba-Riobamba; Dr. Cesar Ayala (Director); Lcda. Guadalupe Guevara; Lcda. Sara VallejoJefe de Enfermeras. (10) Hospital Teófilo Dávila-Machala; Dr. Julio Barzayo (Director); Dr. Emel Romero (Subdirector); Dr. Daniel Solano (Coordinador); Dr. Santillán (Dirección Provincial de Salud). (11) Hospital Básico de Piñas-Piñas; Dr. Germán Gallardo (Director); Lcda. Yasmín CabreraPromotora para la Salud. (12) Hospital Del Puyo-Puyo; Dr. Raúl Villacrés (Director); Yadira Acurio (Coordinadora de Enfermería); Sra.- Isabel Albicha-Encuesta. (13) Hospital
Chillanes-Chillanes; Dra. Martha Cedeño (Directora); Lcdo. César Angulo-Promotor para la Salud. (14) Hospital Francisco de Orellana-El Coca; Dr. Galo Chunca (Director); Lcdo. Digso Zambrano-Educador para la Salud. (15) Área de Salud No. 4-Yanuncay-Cuenca; Dra. Alexandra Rendón (Directora); Dra. Maria F. Andrade. (16) Hospital Isidro Ayora-Loja; Dr. Daniel Astudillo (Director); Lcda. Marisol Ruiz-Trabajadora Social; Lcda. Victoria Briceño-Jefe Enfermeras. (17) Hospital José Maria Velasco Ibarra-Tena; Dr. Alex Vasco (Director); Lcda. Bélgica Ortiz; Ing. Velastegui. (18) Hospital Sagrado Corazón de JesúsQuevedo; Dr. Raúl Duque - Director; Dra. Delfa Espinosa (Coordinadora). (19) Hospital San Luis-Otavalo; Dr. José Terán (Director); Lcda. Adriana Conterón - Educadora para la Salud. (20) Hospital Abel Gilbert Ponton; Dr. César Chong (Director); Lcda. Magdalena Silva-Jefe de Área; Lcda. Maria Elena Aguilar-Educadora para la Salud. (21) Hospital Francisco Icaza Bustamante (Hospital del Niño)Guayaquil; Dra. Patricia Parrales (Directora); Lcda. Zoila Caranqui-Docencia. (22) Hospital José Garcés RodríguezSalinas; Dr. Alfonso Baste (Director); Dr. Pedro Olalla (Coordinador). (23) Hospital Daule-Daule; Dr. Franklin Cantos (Director); Lcda. Ana Jordán-Enfermería. (24) Hospital León Becerra-Milagro; Dr. Mauro García (Director); Dr. Francisco Babadilla (Coordinador) de Área.

\section{References}

[1] C. Mathers, Personal Communication, 2005.

[2] World Health Organization, Cuidado Primario del Oido y Audicion: Manual Avanzado, 2006.

[3] World Health Organization, "Deafness and Hearing Loss," April 2007, http://www.who.int/mediacentre/factsheets/fs300/ en/index.html.

[4] D. Pascolini and A. Smith, "Hearing impairment in 2008: a compilation of available epidemiological studies," International Journal of Audiology, vol. 48, no. 7, pp. 473-485, 2009.

[5] World Health Organization, "Prevention of Deafness and Hearing Impairment," March 2011, http://www.who.int/pbd/ deafness/activities/strategies/en/index.html.

[6] World Health Organization, "Primary Ear and Hearing Care," March 2011, http://www.who.int/pbd/deafness/activities/ hearing_care/en/index.html.

[7] World Health Organization, "National Programmes for Prevention of Deafness \& Hearing Impairment," March 2011, http:// www.who.int/pbd/deafness/activities/national_programmes/en/ index.html.

[8] World Health Organization, "Strategies for Prevention of Deafness and Hearing Impairment," March 2011, http://www .who.int/pbd/deafness/activities/strategies/en/index.html.

[9] World Health Organization, "Epidemiology and Economic Analysis," March 2011, http://www.who.int/pbd/deafness/ activities/epidemiology_economic_analysis/en/index.html.

[10] J. U. Béria, B. C. Raymann, L. P. Gigante et al., "Hearing impairment and socioeconomic factors: a populationbased survey of an urban locality in southern Brazil," Revista Panamericana de Salud Pública, vol. 21, no. 6, pp. 381-387, 2007.

[11] Vicepresidencia de la República del Ecuador, "Ecuador sin Barreras," March 2011, http://www.vicepresidencia.gob.ec/programas. 
[12] Vicepresidencia de la República del Ecuador, "Misión Manuela Espejo," March 2011, http://www.vicepresidencia.gob.ec/programas/manuelaespejo/mision.

[13] Vicepresidencia de la República del Ecuador, "Médicos Ecuatorianos y Cubanos Recorren las Provincias Atendiendo con Calidez a las Personas con Discapacidad," March 2011, http://www.vicepresidencia.gob.ec/programas/manuelaespejo/ mision?start=1.

[14] CONADIS, November2011, http://www.conadis.gob.ec/estadisticas.htm\#estadis.

[15] CONADIS, November 2011, http://www.conadis.gob.ec/registro.htm.

[16] CONADIS, November 2011, http://www.conadis.gob.ec/provincias.php.

[17] World Health Organization, "Grades of Hearing Impairment," January 2008, http://www.who.int/pbd/deafness/hearing_impairment_grades/en/index.html.

[18] G. Kalton, Intorduction to Survey Sampling, Quatitative Applications in the Social Sciences, Sage, Newbury Park, Calif, USA, 1983.

[19] A. Smith, "Demographics of hearing loss in developing countries," in Audiology in Developing Countries, pp. 21-47, Nova Science, New York, NY, USA, 2008.

[20] A. Smith and C. Mathers, "Epidemiology of Infection as a cause of hearing loss," in Infection and Hearing Impairment, pp. 31-66, John Wiley \& Sons, Chichester, UK, 2006.

[21] World Health Organization, "Country Maps of Surveys," March 2008, http://www.who.int/pbd/deafness/survey_map/en/index .html.

[22] M. Saffer and M. Miura, V Manual de OtorrinoLaringologia Pediatrica de la IAPO, Editora e Grafica Vida \& Consciencia, Sao Paulo, Brazil, 2007.

[23] J. Paradise and L. B. Neto, V Manual de Otorrinolaringologia Pediatrica de la IAPO, Editora e Grafica Vida \& Consciencia, Sao Paulo, Brazil, 2007.

[24] S. Caldas, V Manual de Otorrinolaringologia Pediatrica de la $I A P O$, Editora e Grafica Vida \& Consciencia, Sao Paulo, Brazil, 2007.

[25] National Aboriginal Community Controlled Health Organization (NACCHO), The Management of Middle Ear Infection in Aboriginal and Torres Strait Islander Populations, Indigenous and Public Health Media, 2001.

[26] A. Pitkaranta, VManual de Otorrinolaringologia Pediatrica de la IAPO, Editora e Grafica Vida \& Consciencia, Sao Paulo, Brazil, 2007.

[27] World Health Organization, "Strategies for Prevention of Hearing Impairment," March 2008, http://www.who.int/pbd/deafness/activities/strategies/en/index.html.

[28] S. Brosch, L. Michels, P. S. Mauz, H. de Maddalena, and H. Löwenheim, "Factors influencing rehabilitation after sensorineural hearing loss with hearing aids," $H N O$, vol. 53, no. 2, pp. 142-147, 2005.

[29] S. Bertoli, D. Bodmer, and R. Probst, "Survey on hearing aid outcome in Switzerland: associations with type of fitting (bilateral/unilateral), level of hearing aid signal processing, and hearing loss," International Journal of Audiology, vol. 49, no. 5, pp. 333-346, 2010.

[30] L. L. N. Wong, L. Hickson, and B. McPherson, "Satisfaction with hearing aids: a consumer research perspective," International Journal of Audiology, vol. 48, no. 7, pp. 405-427, 2009. 


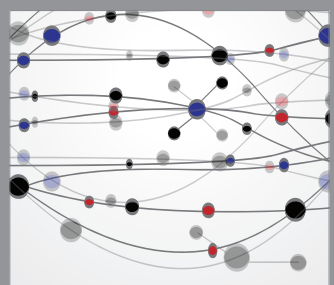

The Scientific World Journal
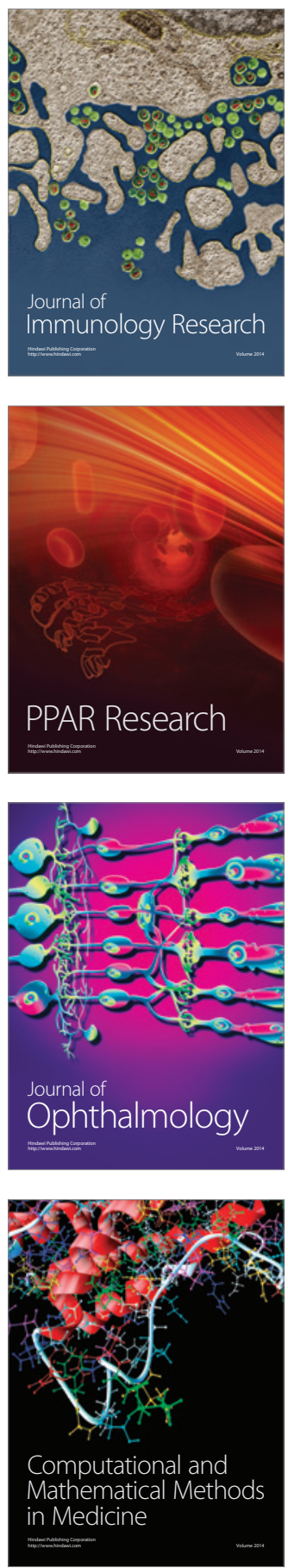

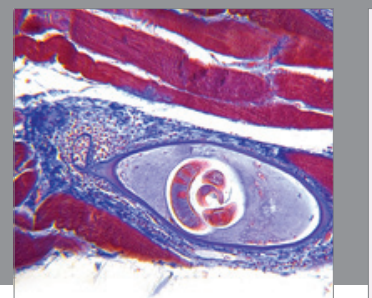

Gastroenterology

Research and Practice
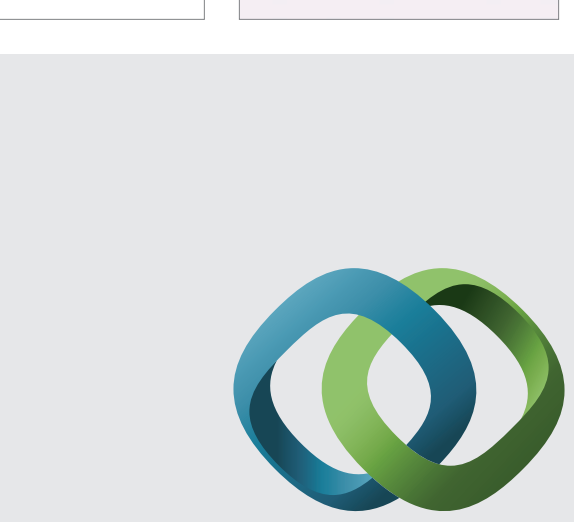

\section{Hindawi}

Submit your manuscripts at

http://www.hindawi.com
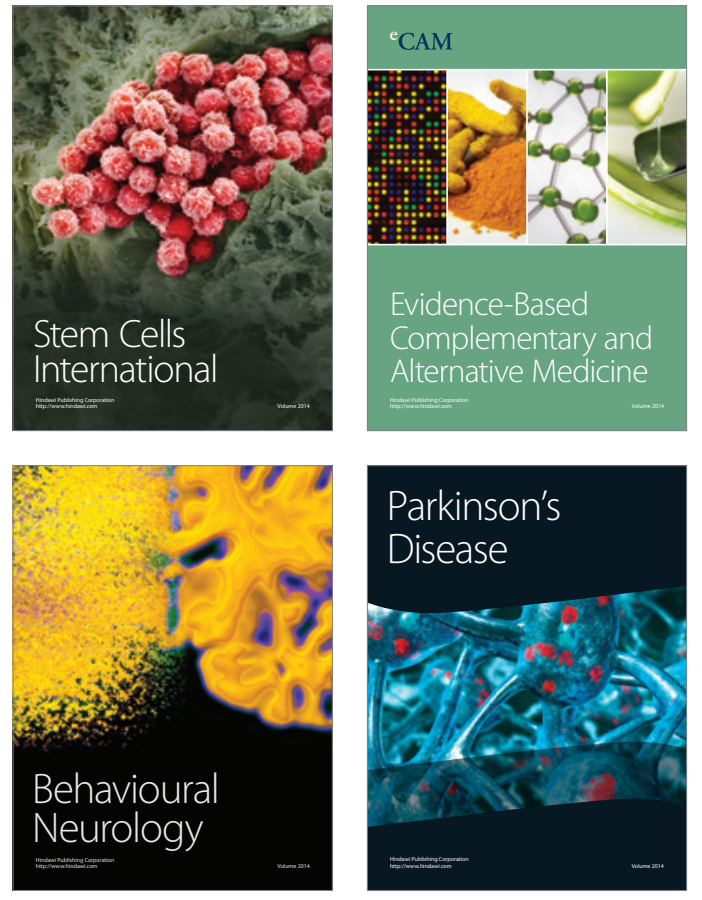
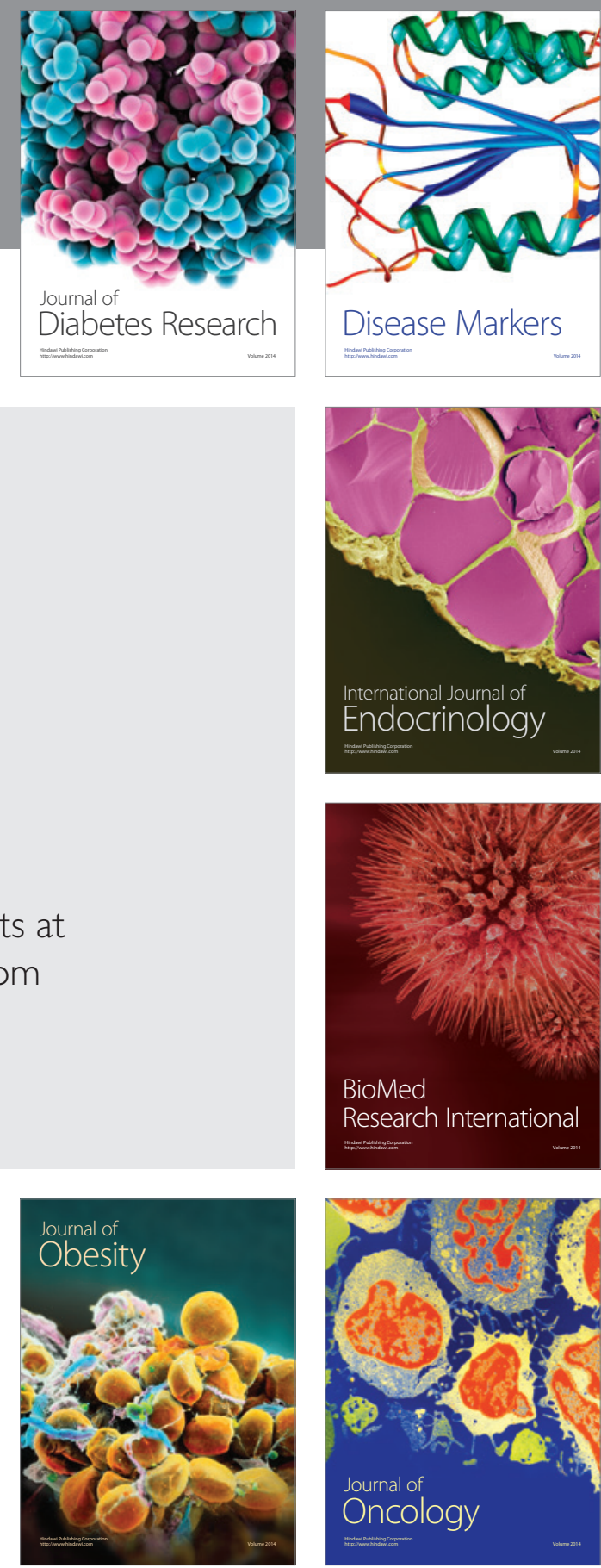

Disease Markers
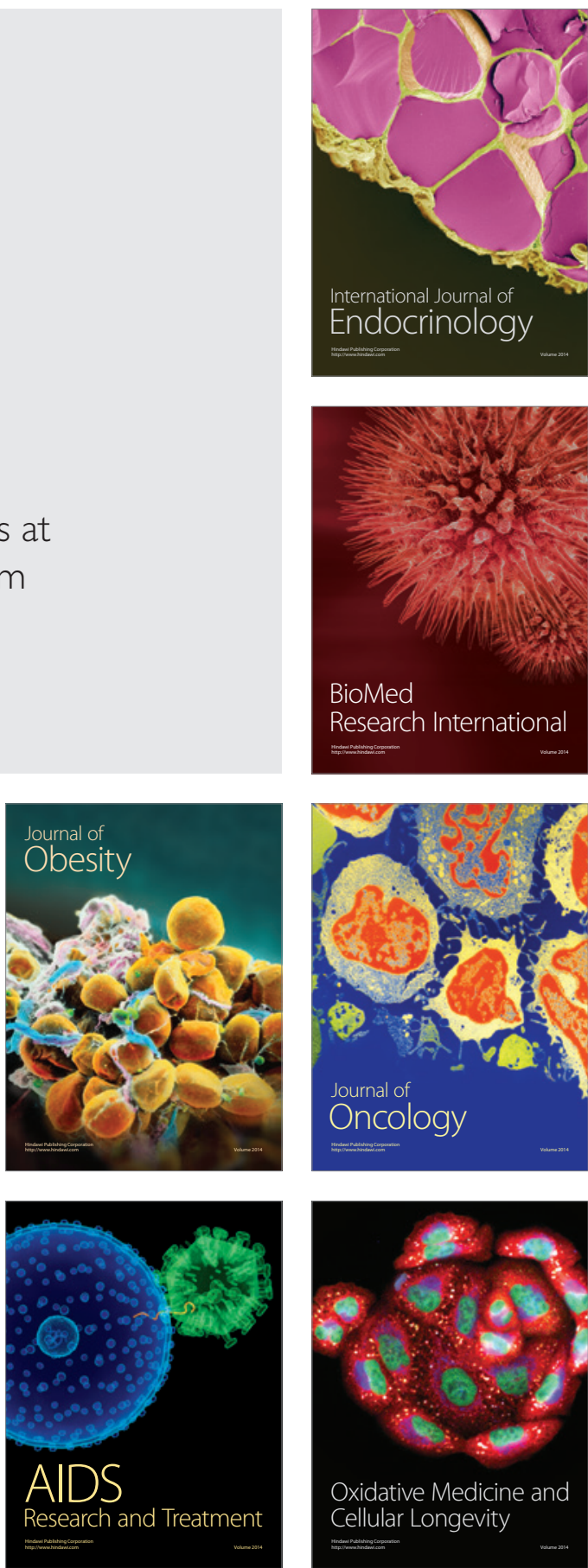